Original Research Article

\title{
Analysis of spontaneously reported adverse drug reactions to pharmacovigilance cell of a tertiary care hospital
}

\author{
Kaksha J. Patel ${ }^{1}$, Ashwin K. Panchasara ${ }^{2 *}$, Manish J. Barvaliya ${ }^{1}$, C. B. Tripathi ${ }^{1}$
}

${ }^{1}$ Department of Pharmacology, Government Medical College, Bhavnagar, Gujarat, India ${ }^{2}$ Department of Pharmacology, GMERS Medical College, Sola, Ahmedabad, Gujarat, India

Received: 19 May 2018

Accepted: 26 June 2018

\section{*Correspondence to:}

Dr. Ashwin K. Panchasara, Email: ashwin_panchasara@ yahoo.com

Copyright: (C) the author(s), publisher and licensee Medip Academy. This is an openaccess article distributed under the terms of the Creative Commons Attribution NonCommercial License, which permits unrestricted noncommercial use, distribution, and reproduction in any medium, provided the original work is properly cited.

\begin{abstract}
Background: The objective of the study was to study the clinical patterns, causality and severity of adverse drug reactions in a tertiary care hospital. Methods: Total 131 ADR forms were collected from January 2012 to December 2012 and evaluated. Patient's characteristics, ADR and drug characteristics, causality, severity and preventability of collected ADR were analyzed.

Results: Total 131 ADR forms were evaluated. Male patient experiencing ADR were more $(73,55.7 \%)$ than female $(58,44.2 \%)$. Adult patients $(12-60$ years) experienced $110(84 \%)$ ADR followed by pediatric patients $(<12$ years $) 11$ $(8.4 \%)$ and geriatric patients (>60 years) 10 (7.63\%). Antimicrobial were the most common group of drugs responsible for ADR followed by NSAIDs and antipsychotic group.

Conclusions: Present study shows lack of awareness among health care professionals for reporting of an ADR. Training and collaboration of health care professionals are needed for improvement in ADR reporting. Appropriate feedback from ADR reporting will help in selection of drug and promotes safer use of drugs.
\end{abstract}

Keywords: Adverse drug reaction, Causality assessment, Pharmacoviglance, Pharmacovigilance Programme of India, Spontaneous reporting

\section{INTRODUCTION}

According to World Health Organization (WHO), Adverse drug reaction (ADR) is defined as " $A$ noxious, unintended and undesirable effect that occurs as a result of dose normally used in man for diagnosis, prophylaxis and treatment of disease or modification of physiological function". ${ }^{1}$ It is a major cause of morbidity and mortality and serious health problem because of major health care cost in patient care. ADR has been found as an important cause for hospital admission which may vary from 0.9 to $7.9 \%$ in proportion. ${ }^{2}$ Poor post marketing surveillance by the pharmaceutical companies and the problem of underreporting of ADR in India has been well known. The rate of reporting of ADR in India is below $1 \%$ while that of world rate is around $5 \% .^{3}$ Because of these factors, the system of ADR reporting should be established very firmly.

There are many methods of ADR detection and reporting. Among all the methods, the spontaneous reporting system (SRS) played a key role in detecting signals from postmarketing surveillance of drugs. Furthermore, this SRS is a useful, effective and widely-used tool to confirm newly developed post-marketing ADRs. ${ }^{4}$ It can detect those ADRs which were not detected in phase 2 or 3 clinical trial. Data from SRS will also determine the risk factors for 
occurrence of serious ADRs. ${ }^{5}$ ADRs from SRS will provide feedback to physician and provide health care safety to patients. ${ }^{6}$ India's contribution to Uppsala Monitoring Database is very little though India has participated in pharmacovigilance programme. ${ }^{7}$ The reasons for the low level of ADR reporting include lack of motivation, awareness, training, and time. An another reason is that the government has not made it mandatory for all health care professionals to report ADRs, unlike some countries like Spain and Sweden. ${ }^{8}$ Physician, resident doctors, nurses and pharmacist plays an important role in spontaneous reporting. The objectives of this study were to identify the risk factors; asses dosing and drug safety; to know characterization of known ADR and generate signal depending on the sample size collected and generate information on the feasibility of such system and take corrective actions to make it better.

\section{METHODS}

The approval of Institutional Review Board (IRB) of Government Medical College, Bhavnagar was taken prior to commencement of the study. We evaluated ADR forms which were spontaneously reported to pharmacovigilance cell of Government Medical College, Bhavnagar, Gujarat from January 2012 to December 2012. Total 131 ADR forms were collected during this period and evaluated. Confidentiality was maintained at all the levels.

\section{Evaluation of data}

\section{Patient characteristics}

Patients' age and gender were consideration for evaluation. Age was divided into 3 groups: Children $(<12$ years old), adults (12-60 years old) and elderly ( $>60$ years old).

\section{Reaction characteristics}

Authors have been used Medical dictionary for Drug Regulatory Affairs (MedDRA) which is an internationally accepted highly specific term for ADR classification. ADRs were classified into System Organ class (SOC) and Preferred Term (PT) according to MedDRA. ${ }^{9}$ Severity of the reaction was determined using modified Hartwig and Siegel scale and classified into mild, moderate and severe reactions. $^{10}$ Causality assessment were done using Naranjo's algorithm. ${ }^{11}$

\section{Drug characteristics}

Drugs involved causing ADR were classified according to drug classes.

\section{ADR form characteristics}

ADR forms were analyzed into completely filled form and incomplete form. The incomplete ADR form was sub classified on the basis of missing information like relevant laboratory investigation, demographic characteristic, seriousness of reaction, outcomes, data of de-challenge, drug details etc.

Forms were also classified in three classes: single drug, multi drug and drugs unknown.

\section{Statistical analysis}

Authors have analyzed these cases using descriptive statistics. The results were reported as frequency of data.

\section{RESULTS}

Total 131 ADR forms were evaluated. Male patient experiencing ADR were more $(73,55.7 \%)$ than female $(58,44.2 \%)$. Adult patients (12-60 years) experienced 110 (84\%) ADR followed by pediatric patients (< 12 years) 11 $(8.4 \%)$ and geriatric patients (>60 years) $10(7.63 \%)$.

According to MedRA classification of ADR, 78.63\% ADR were from Skin and appendages disorders system organ class (SOC) followed by Central and Peripheral nervous system disorder $(5.34 \%)$ and body as a whole-general disorder $(3.05 \%)$. Rashes $(26.71 \%)$ were the most common preferred term followed by urticaria $(12.97 \%)$ and Erythema Multiforme (10.69\%) as shown in Table 1. Antimicrobial were the most common group of drugs responsible for ADR followed by NSAIDs and antipsychotic group. Common individual drug responsible was described in Table 2.

Causality and severity assessment reveals that most of the ADR were in probable and mild category respectively. No ADR were in definite category. On Naranjo's causality scale, more than half $(77 \%)$ of the ADR form were classified as "Probable", 23\% as "Possible" and $0 \%$ as "Definite" (Figure 1).

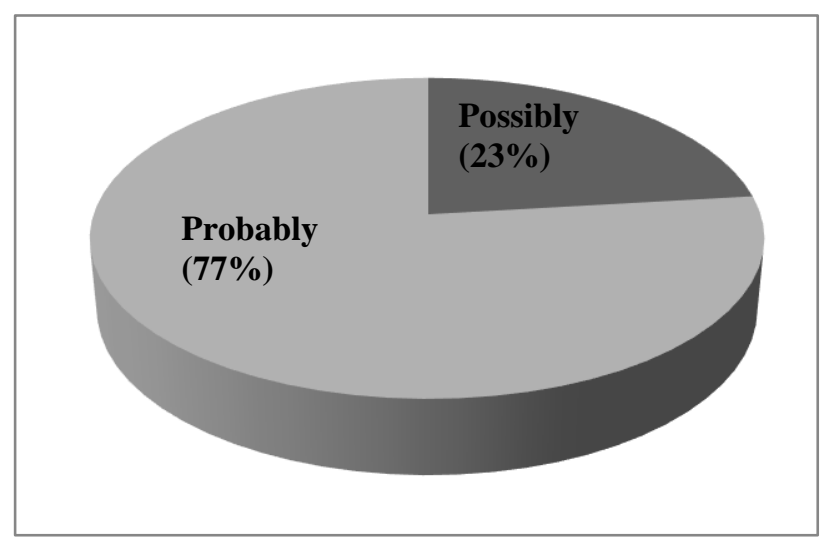

Figure 1: Causality assessment of reported ADR according to Naranjo's algorithm.

According to severity assessment, most of the ADR in this study were mild $(43 \%)$ followed by moderate $(37 \%)$ and severe $(20 \%)$ as shown in Figure 2. There was some 
information which was missing in ADR forms in this study.

In $101 \mathrm{ADR}$ forms, relevant lab investigation was missing, and data of de challenge was missing in 81 ADR forms. Drug details were missing in 10 ADR forms and demographic information was missing in 4 ADR forms. In
56 ADR forms, seriousness of reaction was missing and in 35 ADR forms, outcome of patient was missing (Figure 3). In this study, Single drug was responsible for ADR in 62 $(47.3 \%)$ patients and multiple drugs responsible in 63 (48.1\%) patients while responsible drugs for ADR were not known in $6 \mathrm{ADR}$ forms.

Table 1: Classification of ADR according to MedDRA.

\begin{tabular}{|lll|}
\hline SOC (System Organ Class) & PT (Preferred Term) & No. of cases \\
\hline Skin and appendages disorders & Rashes & $35(26.71 \%)$ \\
\hline & Urticaria & $17(12.97 \%)$ \\
\hline & Erythema Multiforme (EM) & $14(10.69 \%)$ \\
\hline & Fixed eruption & $14(10.69 \%)$ \\
\hline & Stevens Johnson Syndrome (SJS) & $9(6.87 \%)$ \\
\hline & Angioedema & $5(3.82 \%)$ \\
\hline & Exanthema & $4(3.05 \%)$ \\
\hline & Dermatitis & $3(2.29 \%)$ \\
\hline & Itching & $2(1.53 \%)$ \\
\hline Total cases & & $103(78.63 \%)$ \\
\hline Central and Peripheral nervous system disorder & Tremors & $7(5.34 \%)$ \\
\hline & Dystonia & $2(1.53 \%)$ \\
\hline & Convulsions Grand mal & $1(0.76 \%)$ \\
\hline & Giddiness & $1(0.76 \%)$ \\
\hline & Slurring of speech & $1(0.76 \%)$ \\
\hline & Dyskinesia Tardive & $1(0.76 \%)$ \\
\hline Total cases & & $13(9.92 \%)$ \\
\hline Body as a whole-general disorder & Fever & $4(3.05 \%)$ \\
\hline & Periorbital edema & $1(0.76 \%)$ \\
\hline Total cases & & $5(3.82 \%)$ \\
\hline Psychiatric disorders & Impotence & $2(1.53 \%)$ \\
\hline & Libido decreased & $1(0.76 \%)$ \\
\hline & Somnolence & $1(0.76 \%)$ \\
\hline Total cases & & $4(3.05 \%)$ \\
\hline Gastro-intestinal system disorder & Gastric ulcer & $1(0.76 \%)$ \\
\hline & Vomiting & $1(0.76 \%)$ \\
\hline Total cases & Gastritis & $1(0.76 \%)$ \\
\hline White cell and res disorders & & $3(2.29 \%)$ \\
\hline HR and rhythm disorders & Leucopenia & $1(0.76 \%)$ \\
\hline Reproductive disorders, male & Arrhythmia & $1(0.76 \%)$ \\
\hline & Breast discharge & $1(0.76 \%)$ \\
\hline & & \\
\hline & & \\
\hline & & \\
\hline
\end{tabular}

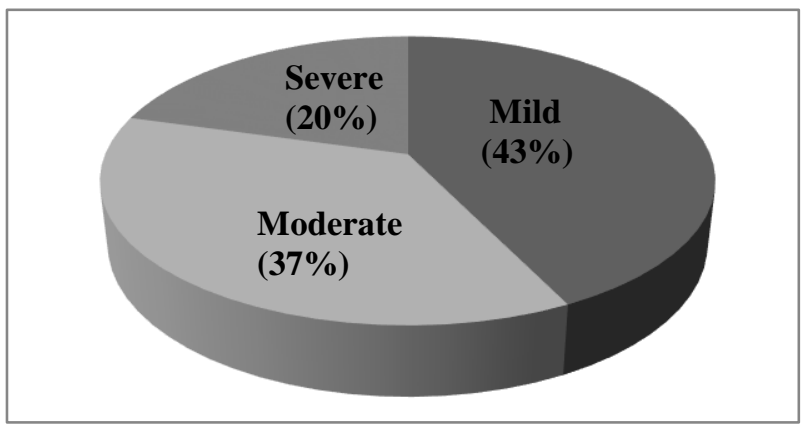

Figure 2: Severity assessment of reported ADR according to modified Hartwig and Siegel scale.

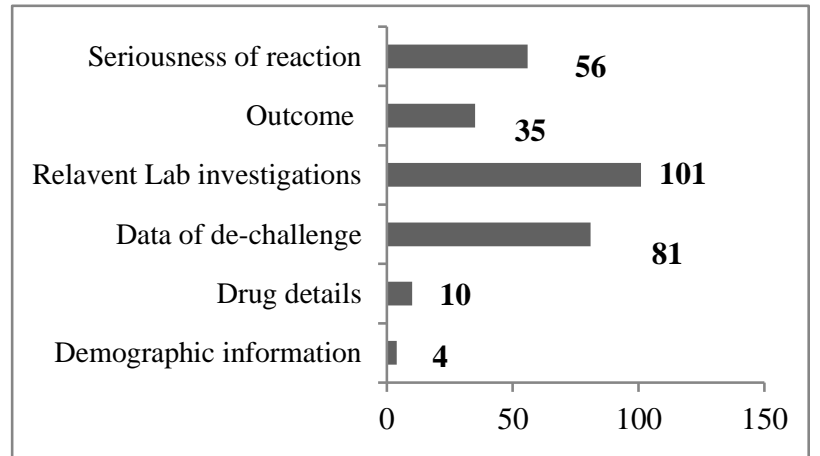

Figure 3: Details of incomplete ADR forms. 
Table 2: Drugs involved in causing ADR (206 drugs/131 ADR forms).

\begin{tabular}{|lll|}
\hline Drugs & No. & $\%(\mathbf{N} / 206)$ \\
\hline Antimicrobial & 82 & 39.80 \\
\hline Penicillin & 20 & 9.7 \\
\hline Cotrimoxazole & 18 & 8.7 \\
\hline Fluoroquinolones & 12 & 5.8 \\
\hline Cephalosporin & 9 & 4.37 \\
\hline Nitroimidazole & 6 & 2.91 \\
\hline Tetracycline & 5 & 2.43 \\
\hline Aminoglycoside & 5 & 2.43 \\
\hline Macrolide & 3 & 1.45 \\
\hline Antifungal & 3 & 1.45 \\
\hline Antiviral & 1 & 0.48 \\
\hline NSAIDs & 29 & 14 \\
\hline Antiretroviral (ART) & 23 & 11.1 \\
\hline Antipsychotic & 19 & 9.22 \\
\hline Antiepileptic & 11 & 5.34 \\
\hline Anti-TB & 10 & 4.85 \\
\hline Antiemetic & 6 & 2.91 \\
\hline Anti-Gastric ulcer & 5 & 2.43 \\
\hline Antimalarial & 5 & 2.43 \\
\hline Antidepressant & 3 & 1.45 \\
\hline Antitumor & 3 & 1.45 \\
\hline Antihistaminic & 2 & 0.97 \\
\hline Vitamins and Minerals & 2 & 0.97 \\
\hline Antiasthmatic & 2 & 0.97 \\
\hline Anticholinergic & 2 & 0.97 \\
\hline Muscle relaxant & 1 & 0.48 \\
\hline Antidiabetic & 1 & 0.48 \\
\hline Total & 206 & \\
\hline & & \\
\hline
\end{tabular}

\section{DISCUSSION}

Pharmacovigilance program of India has been started for monitoring of ADR, safety of patient and creating awareness about spontaneous reporting of ADR in health care professional. All health care professionals like doctors, pharmacist and nurses can report ADR to ADR Monitoring Centre. This program aims to include all the medical colleges as an ADR Monitoring Centre. This centre will analyse the filled ADR forms and send it to WHO Uppsala Monitoring Centre in Sweden.

Age is considered as a risk factor for the occurrence of ADRs. ${ }^{12}$ Children and the elderly people are more prone to ADR because of metabolic system alterations therefore they require careful attention and follow-up to avoid ADR complication and its occurrences. However, in this study, the incidence of ADR in 12-60 years of age group i.e. adult population $(61.0 \%)$ was significantly higher than that in the other age groups. ${ }^{12-14}$ These results seem to contradict those of other study. ${ }^{15}$ It may be because this age group is more vulnerable to diseases like diabetes and hypertension, they frequently visit physician and take medicines. The demographic details in this study show male gender predominance over female. ${ }^{16,17}$ This might be attributed to busy schedule of females in household activities in Indian culture and mentality of ignorance towards health problems. Study by Dang et al, shows female gender predominance for ADR which is opposite to our study. ${ }^{18}$

In this study, most common affected system was skin (35, $26.71 \%$ ) followed by central nervous system 7 (5.34\%) which is similar to other studies. ${ }^{15}$ Few studies also state GIT system involved more than other which is fifth in this study. ${ }^{19}$ It might be because of that physician in the skin department at our institute are more aware about reporting of ADR. Antimicrobial is the most common group of drug responsible for ADR in this study which is similar to study conducted in Nagpur. ${ }^{20,21}$ Shin, et al, reported that cephalosporin was the most frequent responsible group among antibiotics, however, in this study penicillin group of drugs take the first place $(9.7 \%)$ in antimicrobial agent section. $^{22}$ This could be due to prescription pattern and availability of penicillin group of drugs in hospital may be more as compared to other groups of antimicrobial agents. NSAIDS was second most groups of prescribed drugs in this study which may be due to conventional NSAIDs usage is more popular prescription pattern in India.

Causality assessment according to WHO or Naranjo scale and severity assessment according to Modified Hartwig and Siegel's scale shows that 77\% (101) ADR was probable while approximately half of the ADR was mild in type. This may be because in tertiary care hospital rapid detection and treatment of ADR occurs. In evaluation of ADR reporting form, we found that relevant laboratory investigation was missed in most of the forms while drug detail and demographic information was filled in most of the forms which may be due to unawareness among health care professionals about how to fill ADR forms.

The ADR reporting rate is low in this study. The main reason for this low number is that our data were taken from spontaneous reporting. The ADR rate was low as compared to one meta-analysis done by Lazarou et al, who reported that $15.1 \%$ of hospitalised patients develop an ADR. ${ }^{23}$ Other factors that may have contributed to this low number include the non-reporting of mild and common ADRs and the lack of guidelines. Lopez-Gonzalez, et al, stated that low reporting rate was related to clinician in $76 \%$ articles in their bibliographic study using 45 articles about SRS. ${ }^{24}$ Other factors included ignorance of mild ADR (95\%), lethargy for reporting (77\%) and insecurity of individual doctor $(67 \%)$. The lethargy of reporting ADR had very much close relation to accessibility to ADR reporting system. In this case, computerized access to ADR by using internet will be helpful to increase reporting rate of ADR. A recent study about doctors' knowledge, attitude and practices associated with ADR reporting and found that these were inadequate, while another study found that prescribers were aware of ADRs, underreporting and a lack of knowledge of the reporting system were most common. ${ }^{25,26}$ The findings of these studies suggest that doctors need to involved in many 
studies of ADR and ADR reporting should be included in under graduate curriculum.

A total of 30-91\% of ADRs could be avoided and because of that health care resources are saved, and it will improve the safety of patients. ${ }^{27}$ New drugs should be monitored to prevent unknown and severe ADR. Physicians, pharmacists and nurses should work together for prevention of ADR and they should be aware of common clinical problem associated with drug. They should also aware of unusual reaction to food, any medicine or any product. ${ }^{28}$ All health care professional should be motivated for understanding their role in detection, management, and reporting of ADRs.

Since this study was based on SRS, authors were not able to calculate incidence or prevalence of specific ADR symptom on specified drug. They only observed frequent responsible drugs and clinical manifestations of ADRs from our regional areas. Also authors could not apply preventability and predictability of ADR.

\section{CONCLUSION}

Present study shows lack of awareness among health care professionals for reporting of an ADR. Training and collaboration of health care professionals are needed for improvement in ADR reporting. Appropriate feedback from ADR reporting will help in selection of medicine and promotes safer use of drugs.

Funding: No funding sources

Conflict of interest: None declared

Ethical approval: The study was approved by the Institutional Review Board (IRB) of Government Medical College, Bhavnagar, India

\section{REFERENCES}

1. Geneva, Switzerland: World Health Organization. International drug monitoring: The role of hospital; 1969. (Technical report series No. 425)

2. Patel KJ, Kedia MS, Bajpai D, Mehta SS, Kshirsagar NA, Gogtay NJ. Evaluation of the prevalence and economic burden of adverse drug reactions presenting to the medical emergency department of a tertiary referral centre: a prospective study. BMC Cli Pharmacol. 2007;7:8.

3. Prakash S. Pharmacovigilance in India. Indian $\mathbf{J}$ Pharmacol. 2007;39:123-3.

4. Rossi AC, Knapp DE, Anello C, O'Neill RT, Graham $\mathrm{CF}$, Mendelis PS, et al. Discovery of adverse drug reactions: a comparison of selected phase IV studies with spontaneous reporting methods. Jama. 1983 Apr 22;249(16):2226-8.

5. Evans SJ, Waller PC, Davis S. Use of proportional reporting ratios (PRRs) for signal generation from spontaneous adverse drug reaction reports. Pharmacoepidemiol Drug Saf. 2001;10:483-6.
6. Lexchin J. Is there a role for spontaneous reporting of adverse drug reactions? CMAJ. 2006;174(2):191-2.

7. Pimpalkhute SA, Jaiswal KM, Sontakke SD, Bajait CS, Gaikwad A. Evaluation of awareness about pharmacovigilance and adverse drug reaction monitoring in resident doctors of a tertiary care teaching hospital. Ind J Med Scienc. 2012 Mar 1;66.

8. Brewer T, Colditz GA. The post marketing surveillance and adverse drug reactions: the current perspectives and future needs. JAMA 1999;281(9):824-9.

9. Introductory Guide MedDRA Version 14.0. March 2011. MSSO-DI-6003-14.0.0. Available at: http://www.who.int/medical_devices/innovation/Med DRAintroguide_version14_0_March2011.pdf Last accessed on 2018 May 31.

10. Naranjo CA, Busto U, Sellers EM, Sandor P, Ruiz I, Roberts EA, et al. A method for estimating the probability of adverse drug reactions. Clinical Pharmacology \& Therapeutics. 1981 Aug 1;30(2):239-45.

11. Hartwig, SC, Siegel J, Schneider PJ. Preventability and severity assessment in reporting adverse drug reactions. A J Pharmacovigil. 1999;49(1):2229-32.

12. Pirmohamed M, James S, Meakin S, Green C, Scott AK, Walley TJ, et al. Adverse drug reactions as cause of admission to hospital: prospective analysis of 18 820 patients. BMJ. 2004 Jul 1;329(7456):15-9.

13. Notteerman DA. Pediatric Pharmacotherapy, Pharmacology in Therapy. Intensive. Rio de Janeiro: Revinter; 1993:96-120.

14. Vora MB, Trivedi HR, Shah BK Tripathi CB. Adverse drug reactions in inpatients of internal medicine wards at a tertiary care hospital: A prospective cohort study. J Pharmacol Pharmacother. 2011 Jan;2(1):21-5.

15. Lee JH, Park KH, Moon HJ, Lee YW, Park JW, Hong CS. Spontaneous Reporting of Adverse Drug Reactions through Electronic Submission from Regional Society Healthcare Professionals in Korea. Yonsei Med J. 2012;53(5):1022-7.

16. Louro EO. Profile of use of drugs and monitoring of adverse reactions in pediatric patients at the Albert Sabin Hospital in São Paulo. 2004;41:23-9.

17. Arulmani R, Rajendran SD, Suresh B. Adverse drug reaction monitoring in a secondary care hospital in South India. $\mathrm{Br}$ J Clin Pharmacol. 2008 February;65(2):210-6.

18. Dang A, Bhandare PN. The profile of voluntary reported adverse drug reactions at a tertiary care hospital: a fifteen month prospective study. Journal of clinical and diagnostic research: JCDR. 2012 Nov;6(9):1504.

19. Sriram S, Ghasemi A, Ramasamy R, Devi M, Balasubramanian R, Ravi TK, et al. Prevalence of adverse drug reactions at a private tertiary care hospital in south India. J Res Med Sci. 2011 Jan;16(1):16-25.

20. Shrivastava M, Uchit G, Chakravarti A, Joshi G, Mahatme M, Chaudhari H. Adverse drug reactions reported in Indira Gandhi Government Medical 
College and Hospital, Nagpur. J Assoc Physicians India. 2011 May;59:296-9.

21. Arulmani R, Rajendran SD, Suresh B. Adverse drug reaction monitoring in a secondary care hospital in South India. $\mathrm{Br}$ J Clin Pharmacol. 2008 February;65(2):210-6.

22. Shin YS, Lee YW, Choi YH, Park B, Jee YK, Choi SK, et al. Spontaneous reporting of adverse drug events by Korean regional pharmacovigilance centers. Pharmacoepidemiology and drug safety. 2009 Oct;18(10):910-5.

23. Lazarou J, Pomeranz BH, Corey PN. Incidence of adverse drug reactions in hospitalized patients: A meta-analysis of prospective studies. JAMA 1998;279:1200-5.

24. Lopez-Gonzalez E, Herdeiro MT, Figueiras A. Determinants of under-reporting of adverse drug reactions: a systematic review. Drug Saf. 2009;32:1931.

25. Chopra D, Wardhan N, Rehan HS. Knowledge, attitude and practices associated with adverse drug reaction reporting amongst doctors in a teaching hospital. Int J Risk Saf Med. 2011;23(4):227-32.

26. Desai CK, Iyer G, Panchal J, Shah S, Dikshit RK. An evaluation of knowledge, attitude, and practice of adverse drug reaction reporting among prescribers at a tertiary care hospital. Perspect Clin Res. 2011;2(4):129-36.

27. Puerro MAP. The cost of adverse reactions medicinal products in hospitals. MSc thesis. University of São Paulo, Faculty of Public Health; 2004.

28. Dohme MS. General Aspects of Medications. In Manual. Merck. Health for the Family: Section 2 Medications. Chapter 5. Available at: http://mmspf.msdonline.com.br/pacientes/manual_me rck/secao_02/cap_005.html.

Cite this article as: Patel KJ, Panchasara $\mathrm{AK}$, Barvaliya MJ, Tripathi CB. Analysis of spontaneously reported adverse drug reactions to pharmacovigilance cell of a tertiary care hospital. Int J Basic Clin Pharmacol 2018;7:1551-6. 